\title{
TURISMO DE ALDEIA E DESENVOLVIMENTO TURÍSTICO REGIONAL: ANÁLISE COMPARATIVA ENTRE A REGIÃO CENTRO PORTUGUESA E A DA REGIÃO DE CASTELA E LEÃO
}

VILLAGE TOURISM AND REGIONAL TOURISTIC DEVELOPMENT: COMPARATIVE ANALISIS FROM CENTER OF PORTUGAL AND CASTILE AND LEON

TURISMO DE ALDEA Y DESAROLLO TURISTICO REGIONAL: ANALISIS COMPARATIVA DE REGIÓN CENTRO DE PORTUGAL Y LA REGIÓN DE CASTILLA Y LEÓN

\author{
Manuel Salgado (manuelsalgado@ipg.pt)* \\ José Martins (jasvm@ipg.pt)** \\ Eva Lahuerta (eva.lahuerta@usal.es)*** \\ Rebeca Cordero (rcorderogu@upsa.es)****
}

\section{RESUMO}

Os principais conceitos do turismo de aldeia enquadram-se no contexto do turismo rural, que interessa conhecer para estimular a sustentabilidade e a competitividade no desenvolvimento turístico transfronteiriço entre a região Centro, em Portugal, e a região de Castela e Leão, em Espanha. Assim, pretende-se estruturar um modelo de desenvolvimento turístico adequado a uma gestão mais integrada destas regiões, que registam problemas sociais e económicos estruturantes que, por consequência, também se traduzem em desequilibrios dos sistemas ambiental e cultural. Os estudos de caso aprofundados no estudo empírico incidem sobre duas zonas rurais similares (a Serra da Estrela, na região Centro, e a Sierra de Francia, na região de Castela e Leão) e têm por intuito permitir uma análise de comentários no Facebook. A recolha de dados em setembro de 2016 permitiu a análise com o programa Nvivo. A estrutura desta pesquisa inicia-se com a discussão acerca dos conceitos de turismo de interior, de turismo rural e de turismo de aldeia. Depois caracteriza-se as regiões objeto do estudo empí- 
rico; especifica-se as opções metodológicas do trabalho de campo, para garantir a comparação e registar diferenças nos dois casos de estudo. O quarto ponto do artigo visa a análise e discussão dos dados obtidos a partir de redes sociais,

Palavras-chave: Turismo de interior, turismo rural, turismo de aldeia, desenvolvimento regional, redes sociais.

\section{ABSTRACT}

The main concepts of village tourism are framed in the rural tourism context, which is important to know in order to stimulate sustainability and competitiveness in the cross-border tourism development between the Central region of Portugal and the region of Castile and León. Thus, we wish to structure an adequate touristic development model to a more integrated management of these areas that register social and economic structural problems that, consequently, also contribute to imbalances of the environmental and cultural systems. The case studies based on empirical studies focus on two similar rural areas (Serra da Estrela in central region of Portugal and the Sierra de Francia in the region of Castile and León) and are intended to allow for an analysis of comments on Facebook. The data collection in September 2016 allowed an analysis with the program Nvivo. The structure of this research begins with the discussion of inland, rural and village tourism. We then analyse the regions of the empirical study and then specify the methodological options of the fieldwork to guarantee the comparison and establish differences in the two case studies. The fourth point of the article aims at analysing and discussing the data obtained from the reality observed from social networks, which are powerful sources of systematization of secondary data to understand behaviours and attitudes of tourist demand.

keywords: Rural tourism, rural tourism, village tourism, regional development, social networks.

\section{RESUMEN}

Los principales conceptos del turismo de aldea se encuadran en el contexto del turismo rural, que interesa conocer para estimular la sostenibilidad y la competitividad en el desarrollo turístico transfronterizo entre 
la región Centro de Portugal y la región de Castilla y León, en España. Así, se pretende estructurar un modelo de desarrollo turístico adecuado a una gestión más integrada de estas regiones, que registran problemas sociales y económicos estructurantes que, por consiguiente, también se traducen en desequilibrios de los sistemas ambiental y cultural. Los estudios de caso profundizados en el estudio empírico inciden sobre dos zonas rurales similares (la Serra da Estrela, en la región Centro, y la Sierra de Francia, en la región de Castilla y León) y tienen el propósito de permitir un análisis de comentarios en Facebook. La recogida de datos en septiembre de 2016 permitió el análisis con el programa Nvivo. La estructura de esta investigación comienza con la discusión del turismo de interior, rural y de aldea. Luego analiza las regiones del estudio empírico y, a continuación, especifica las opciones metodológicas del trabajo de campo para garantizar la comparación y registrar diferencias en los dos casos de estudio. El cuarto punto del artículo se refiere al análisis y discusión de los datos obtenidos de la realidad observada a partir de redes sociales, que son fuentes poderosas de sistematización de datos secundarios para la comprensión de los comportamientos y actitudes de la demanda turística.

Palabras clave: Turismo de interior, turismo rural, turismo de aldea, desarrollo regional, redes sociales.

\footnotetext{
* Professor Adjunto do Instituto Politécnico da Guarda (IPG). Membro das Unidades de Investigação UDI/ IPG, GITUR/IPLeiria e GOVCOPP/UA.

** Professor Adjunto do Instituto Politécnico da Guarda. Membro da UDI/IPG.

*** Profesora Ayudante Doctor del Departamento de Administración y Economía de la Universidad de Salamanca. Miembro del Instituto Multidisciplinar de Empresa.

**** Profesora Asociada en Universidad Pontificia de Salamanca. Miembro del Instituto Multidisciplinar de Empresa de la Universidad de Salamanca.
} 


\section{INTRODUÇÃO}

O modelo de desenvolvimento turístico de um território, sobretudo no interior de um país, deve ser associado às potencialidades dos seus recursos endógenos, designadamente às aldeias características da região. Estas constituem-se como atrativos turísticos num destino eminentemente rural que, segundo o critério da amplitude territorial, é o recurso natural ou cultural que atrai o turista a visitar esse destino (Cunha e Abrantes, 2013). Assim, as políticas e as estratégias de organização em rede, a nível regional e sub-regional, devem visar um desenvolvimento turístico sustentável e competitivo. Neste âmbito escolhe-se uma sub-região portuguesa (Serra da Estrela na região Centro) e uma espanhola (Sierra de Francia na região de Castela e Leão) para serem estudos de caso para análise comparativa.

Neste estudo pretende-se construir um modelo de desenvolvimento turístico que pressuponha uma gestão mais integrada destas regiões, pelo que consideram-se os seguintes objetivos operacionais: compreender o potencial do turismo de aldeia, num âmbito rural e de territórios de interior; identificar e analisar os projetos transfronteiriços com maior interesse para uma gestão integrada nas duas regiões; desenvolver um "novo" produto (turismo de aldeia) numa dinâmica transfronteiriça, de acordo com as experiências da procura turística de 2 sub-regiões.

No lado da oferta turística desenvolve-se a análise comparativa de experiências de redes de desenvolvimento turístico realizadas a nível das duas regiões fronteiriças. Esta tem em vista proceder, depois, a uma análise sistemática dos comentários numa rede social (Facebook), para interpretar a perspetiva da procura turística nas sub-regiões escolhidas. A recolha de dados foi realizada em setembro de 2016. Os dados foram tratados com o programa Nvivo, para ajudar a responder acerca da veracidade das 2 hipóteses do estudo. A metodologia é de cariz mais qualitativo e exploratório, pois considera a perspetiva dos turistas que procuram experiências em âmbito rural.

O enquadramento teórico aborda o turismo de interior, rural e de aldeia, que constituem abordagens importantes ao turismo regional. No segundo ponto analisa-se o enquadramento desta região transfronteiriça. No seguimento apresenta-se a metodologia do estudo empírico apoiada no estudo de caso. No quarto ponto analisa-se os dados obtidos no 
Facebook, para interpretar atitudes a nível da procura turística e, assim, contribuir para a coesão desta região alargada de cariz rural.

\section{TURISMO DE ALDEIA E DESENVOLVIMENTO SUS- TENTÁVEL A NÍVEL REGIONAL 1.1. TURISMO DE ALDEIA COMO POTENCIADOR DO DESENVOLVIMENTO SUSTENTÁVEL}

A Organização Mundial do Turismo (OMT) indica a importância do turismo sustentável por salvaguardar o ambiente e os recursos naturais, garantindo o crescimento económico da atividade, ou seja, por ser capaz de satisfazer as necessidades das presentes e futuras gerações. O turismo e o lazer assumem uma importância crescente ao nível da sua relação com os sistemas ambiental, social, económico e cultural, entre outros sistemas com os quais o sistema turístico estabelece interações fundamentais (Cunha e Abrantes, 2013: 104). É neste contexto que se interpreta que o turismo de aldeia pode ajudar a reverter alguns desequilibrios, que se registam de modo preocupante nos ecossistemas social, cultural e ambiental, em regiões classificadas de interior e com um despovoamento acentuado.

Os processos de planeamento e de desenvolvimento turístico a nível regional, muito particularmente em áreas predominantemente rurais e naturais, podem ser facilmente associados ao modelo integrado de turismo de aldeia. Os desafios do mundo rural incluem o turismo como setor essencial com vista à sua refuncionalização no âmbito de um desenvolvimento equilibrado numa base económica regional diversificada. Augusto et al. (2010) defendem a necessidade de uma análise integrada multissectorial e pluridimensional no território. Estes autores baseiam-se no estudo dos resultados obtidos nos quadros comunitários que, em parte, contribuíram para inibir a integração ao nível da pluridimensionalidade (políticas territoriais) e da multissectorialidade (políticas sectoriais), que se tornam estratégias necessárias sobretudo para o espaço rural. Neste contexto sugerem um paradigma de atuação nas áreas rurais de baixa densidade com vocação turística centrado na abordagem integrada e territorializada (Augusto et al., 2010: 499).

A participação das populações locais torna-se uma estratégia funda- 
mental de envolvimento dos agentes interessados no desenvolvimento turístico sustentado do seu território de vida quotidiana. Augusto et al. (2010: 501) referem que a focalização no desenvolvimento endógeno "faz emergir novas formas de governação - abordagem bottom-up, modelo que visa a construção partilhada e participada de uma nova visão para o território, refletindo-se aqui o princípio da descentralização e o conceito de empowerment como fórmula de se atingir o desenvolvimento sustentável".

Segundo Dias (2013: 189), as áreas de baixa densidade no contexto rural, ainda que com tendência regressiva, têm sido alvo de estratégias assistencialistas que incapacitam a reinvenção dos territórios, reduzindo - os ao quadro de meros produtores de bens primários para o abastecimento do meio urbano. O desafio passa, assim, por evoluir para a construção e aplicabilidade de medidas que incorporem projetos integrados, nos quais se privilegie a participação, o crescimento de base territorial, a capacitação como estímulo ao empowerment, o trabalho colaborativo, a inovação e a complementaridade, em detrimento do puro assistencialismo. Neste contexto, pretende-se ensaiar um paradigma que tem como intuito servir de apoio ao processo de desenvolvimento em áreas de baixa densidade. $O$ enfoque reside no apoio ao processo de desenvolvimento em áreas de baixa densidade para a valorização económica dos recursos endógenos, no qual a abordagem integrada e a inovação são dois pilares que dão valor às dotações fatoriais existentes, por exemplo, nas Aldeias Histórias de Portugal, preservando e valorizando o seu património material e imaterial.

A relevância do processo de planeamento e desenvolvimento turístico torna-se ainda mais importante quando se estudam territórios de baixa densidade populacional, como as aldeias rurais, que se encontram distribuídas por todo o interior peninsular. Aldeias que têm sofrido transformações profundas nas últimas décadas, essencialmente devido ao êxodo para os meios urbanos, bem como ao abandono progressivo das atividades económicas tradicionais. Estes territórios, riquíssimos do ponto de vista dos recursos naturais e culturais, são normalmente detentores de um vasto património arquitetónico, aliado a um admirável património paisagístico e cultural. Neste contexto, Rodrigues e Rodrigues (2009: 42) referem que as áreas rurais "enfrentam grandes limitações em termos de desenvolvimento, causadas pelo aumento do 
isolamento, pela degradação das atividades económicas e pelo consequente aumento do desemprego. Para além disso, essas regiões estão a sofrer o fenómeno do envelhecimento da população e da desertificação humana, assim como outros fatores que influenciam negativamente o seu processo de desenvolvimento. Muitas das pessoas que nasceram nessas regiões não têm possibilidade de ficar e consequentemente migram para os centros urbanos. Para contrariar esta tendência, é necessário promover iniciativas que contribuam para um desenvolvimento sustentável dessas regiões. Apesar dos constrangimentos, essas regiões possuem um grande potencial sendo áreas com uma forte preservação ambiental e que possuem uma vasta riqueza cultural e etnográfica que pode ser usada para estas iniciativas." Assim, nos territórios rurais que possuem vocação turística, devem-se implementar estratégias de desenvolvimento turístico que tenham por base os recursos endógenos do território, bem como as suas gentes. De facto, o reconhecimento da importância da atividade turística nas áreas rurais de baixa densidade tem sido unânime, quer no meio político quer no académico, em virtude dos recursos existentes e do decréscimo da importância da atividade primária no mundo rural (Augusto et al., 2010). Por este motivo, enquanto estratégia de planeamento e desenvolvimento turístico a nível regional e/ou sub-regional, o turismo de aldeia poderá constituir uma mais-valia para estes territórios, na medida em que, pelo facto de constituir uma estratégia para o turismo sustentável, poderá ajudar a contribuir para a união de "energias" dos atores turísticos e de suporte às atividades ainda "resistentes" em territórios de baixa densidade e crescentemente desumanizados.

O destino turístico é o resultado de um território que passou pelo processo de desenvolvimento da atividade turística, originando novas relações numa nova realidade económica mais alargada, sobretudo pela capacidade de atrair e de satisfazer os turistas. Buhalis (2000) caracteriza os destinos como uma mistura de produtos turísticos que oferecem uma experiência integrada aos consumidores. Os turistas consomem os destinos através da sua marca/nome do destino, tendo por base condicionantes pessoais subjetivas como o itinerário, os motivos da visita, o nível educativo e cultural e experiências anteriores. Kotler et al. (2010), relativamente aos limites espaciais de um destino turístico, afirmam que podem ser reais ou percebidos, com fronteiras criadas pelo 
mercado ou pelos elementos do destino. Muitas vezes, os destinos turísticos estão divididos por barreiras físicas e administrativas que não têm em consideração as preferências dos turistas ou o posicionamento da indústria turística.

Buhalis (2000) dá o exemplo dos Alpes partilhados pela França, Suíça, Itália e Áustria, que são percebidos e consumidos como sendo um produto turístico único, apesar dos limites fronteiriços entre os quatro países. Este exemplo pode também ser adaptado ao caso do rio Alva, partilhado por 5 concelhos. Assim, tendo por base uma ideia de cadeia de valor, as atividades a montante, investigação e desenvolvimento de produtos, atividades de suporte, operações e logística são atividades profícuas para a cooperação entre concorrentes. $O$ produto turístico caracteriza-se por ser uma complexa amálgama de serviços. Do ponto de vista do consumidor, o produto turístico é um conceito subjetivo e depende fortemente da imagem e das expectativas que possui do lugar/destino. O produto turístico para Kotler et al. (2010) são objetos físicos, serviços, destinos, organizações e ideias que satisfazem um desejo ou necessidade.

Segundo Kastenholz et al. (2014: 13), "a experiência turística em meio rural, entendida como uma experiência global do destino, vivida pelos visitantes de territórios rurais, envolve uma grande quantidade e variedade de recursos, atrações, serviços, pessoas e ambientes, nem todos desenhados especificamente para utilização turística, mas que condicionam a experiência vivida e são alvo de procura turística. Assim, o potencial da experiência turística nestes destinos rurais está muito dependente dos recursos e do património (material e imaterial) existentes nas Aldeias e no território envolvente". Tendo em consideração o Projeto Overall Rural Tourism Experience (ORTE), desenvolvido por estas autoras, as diversas dimensões do contexto das três Aldeias analisadas, que têm como denominador comum o facto de terem beneficiado de investimento público para a preservação do seu património e para o reforço da sua atratividade turística deverão, neste sentido, ser um projeto inacabado pela necessidade de investimento contínuo nestes territórios. As aldeias em apreço são: Janeiro de Cima, pertencente à rede das Aldeias do Xisto; Linhares da Beira, integrada na rede das Aldeias Históricas de Portugal; e Favaios, que integra a rede das Aldeias Vinhateiras. 
Na abordagem destas 3 redes de aldeias em Portugal, Capela e Figueiredo (2014: 377) também abordam a promoção do rural, pois consideram que o turismo e as atividades associadas "têm-se constituído como centrais, sendo frequentemente apontados como mecanismos de revitalização e desenvolvimento local. A promoção turística constitui-se como um aspeto muito relevante na representação, consumo e reconfiguração de muitos destes territórios, contribuindo para a formação de um imaginário social sobre o rural através da sua apresentação frequente como espaço idilico e pleno de oportunidades de recreio". A reflexão sobre o modelo de turismo de aldeia supõe uma gestão mais integrada a nível regional transfronteiriço com vista a equacionar o desenvolvimento sustentável, daí se analisar a importância que a fronteira pode ter como elemento promotor de sinergias entre os agentes turísticos existentes nas duas regiões em análise.

\subsection{FRONTEIRA E DESENVOLVIMENTO REGIONAL}

Desde a integração comunitária em 1986, que marcou a agenda geopolítica de Portugal e Espanha, que se verifica uma produção científica crescente e significativa a abordar as questões transfronteiriças "de forma frutífera na sua análise multissetorial sobre este âmbito da fronteira" (López, 2013: 37). Neste caso interessou estudar e compreender a raia ibérica na região de Castela e Leão com Portugal, sobretudo numa perspetiva de turismo de fronteira. Este estudo estava enquadrado nos projetos da Rede Ibérica de Entidades Transfronteiriças (RIET), que visa a promoção da cooperação e o desenvolvimento integrado dos dois lados da fronteira dos países ibéricos. Entre outros autores, destaca-se Moreno (2013: 76) pela análise incisiva no turismo na região de fronteira de Castela e Leão com vista a desenvolver o contexto competitivo, sobretudo permitindo compreender a importância dos produtos turísticos da região e também compreender os principais motivos da visita dos seus habitantes a Portugal, destacando a gastronomia com 37,9\%, pelo que é assim valorizada a restauração portuguesa. López-Guzmán et al. $(2015: 9,11)$ refletem sobre os contributos da gastronomia em destinos turísticos fronteiriços em desenvolvimento e analisam um estudo de caso (República Dominicana e Haiti) para compreender a realidade e constatam que a motivação principal da procura está relaciona 
com a comida e bebida. Partem do pressuposto que, "em zonas fronteiriças em vias de desenvolvimento, o turismo forma parte do motor da sua economia, sendo explorado através de diferentes recursos histórico-culturais e naturais próximos da fronteira" e que entre estes recursos está a gastronomia. Neste âmbito acreditam que "o território turístico fronteiriço é concebido não apenas com base nos seus atributos físicos como se poderia pensar à primeira vista, mas também há que reparar nos componentes simbólicos, surgindo assim o conceito de construção social do espaço turístico". Dado a gastronomia ser um valioso património reconhecido em Portugal e Espanha, em particular devido à "dieta mediterrânica", quer pela riqueza alimentar de produtos quer pela sua diversidade, promove-se assim a circulação de visitantes dos dois lados da fronteira pela motivação por este produto de turismo gastronómico, que pode ser particularmente importante em espaços rurais. A obra Turismos de Interior (Arcos, 2013) aborda com especial incidência uma parte designada Planificación, Comercialización y Experiencias, constituindo um trabalho incontornável para a discussão da temática deste trabalho, pois inclui alguns artigos que especificam mesmo as atividades turísticas na zona de fronteira de Castela e Leão e as regiões Norte e Centro de Portugal, como espaços de interior e de baixa densidade populacional (Mínguez, 2013: 139-157; em Arcos, 2013). Este artigo discute, em particular, a fronteira como território de encontro e a importância da cooperação transfronteiriça, o trabalho em rede e a governança territorial, que nos interessa aplicar à região Centro e à de Castela e Leão. De modo complementar destaca-se, entre outros artigos, o de Milagros (2013: 161-175; em Arcos, 2013), que visa a análise da comercialização do turismo de interior, constituindo uma perspetiva aprofundada da Comercialização, Comunicação e Marketing, com vista a ajudar a compreender a atualidade e as tendências na distribuição turística aplicada em especial ao turismo de interior, como é o caso de Castela e Leão. A análise ampla do mercado turístico, a partir das óticas da procura e da oferta, destaca a quarta parte da obra que incide sobre as experiências turísticas em meio natural e os novos produtos turísticos de interior, permitindo uma abordagem sobre os espaços naturais da região de Castela e Leão e o potencial particular do turismo rural, do enoturismo e do turismo ativo.

Mateus et al. (2009) desenvolveram um trabalho de reflexão com vista a 
criar uma nova estratégia para a cooperação Castela e Leão e a região Centro, sobretudo no contexto das dinâmicas de crescimento das duas regiões e das políticas comunitárias de apoio ao desenvolvimento dos territórios com maior atraso, entre as quais se encontravam estas duas regiões. Na componente de turismo refere-se que o conjunto das regiões tem características e recursos que sustentam "um bom potencial para o desenvolvimento turístico, sobretudo se forem tomadas algumas decisões estratégicas sobre conjuntos de produtos-mercados específicos a desenvolver e se forem ultrapassados alguns problemas estruturais (Mateus et al, 2009: 133). Neste estudo consideram-se que os produtos-mercados mais relevantes para o desenvolvimento de iniciativas conjuntas são: turismo de natureza/turismo ativo/ecoturismo; turismo cultural, turismo rural, turismo gastronómico e enoturismo, touring cultural e paisagístico. Nesta integração multiproduto pretendese valorizar o desenvolvimento de produtos verdadeiramente compósitos, mais apelativos para o turista, com base nas redes e parcerias, quer no âmbito local e regional, quer transfronteiriço.

Aguado (2013: 127) reflete sobre o planeamento turístico da região de Castela e Leão desde 1995 e refere que existe um grande dinamismo neste setor, pelo que "a planificação do setor turístico requer flexibilidade, para adaptar-se às possíveis mudanças. Já não basta unicamente definir os objetivos, organizar os recursos e avaliar as políticas públicas. É necessário dar uma estrutura a esta planificação e a possibilidade de desenvolvimento que permita uma adaptação permanente da política turística que se desenvolve neste ambiente de mudança". Aguado (2013) refere que houve uma evolução na planificação territorial, com os sucessivos planos estratégicos de turismo, pois assentam quase exclusivamente nas características espaciais do destino. $\bigcirc$ enfoque é no turismo de produto turístico, que se desenvolve em determinado território, que é reforçado através de Planos de Competitividade do Produto Turístico. Neste âmbito, a Lei 14/2010 (Aguado, 2013: 131), que regula a Planificação Turística na região, no cap. V - Ordenación, Fomento y Promocion del Turismo, artigo 57 e ponto 4, refere a promoção de cenários de "colaboração com outras administrações públicas, com outras regiões da União Europeia, especialmente com as regiões fronteiriças de Portugal, para pôr em marcha planos e programas de atuação conjunta". Como se comprova nesta Lei, existe uma 
formalização da importância de colaboração em matéria turística entre as duas regiões analisadas no nosso trabalho, que merece ser analisada, interpretada e discutida, também por académicos dos dois lados da fronteira. Neste plano avança-se no eixo da Integração da Oferta para um turismo mais sustentável, estando considerados 5 espaços naturais da Carta Europeia de Turismo Sustentável, designadamente o Parque Natural Las Butuecas - Sierra de Francia (Salamanca), que é um dos estudos de caso deste estudo, que será comparada em Portugal com a Serra da Estrela, na região fronteiriça do Centro. Dado o interesse do turismo rural, em particular, refere-se ainda que, no âmbito da Promoção e Cooperação Comercial, também se destaca a Central de Reservas de Turismo Rural de Castilla y León, por ter potenciado o aumento significativo da procura em alojamentos turísticos da região.

Pereira e Pereira (2014: 286-287) analisam o turismo transfronteiriço luso-galego e consideram-no como instrumento de cooperação em âmbitos como a promoção, a articulação empresarial e as mobilidades transfronteiriças. Neste caso, reconhece-se que a raia se está a transformar em património cultural (e natural) e, por consequência, num produto turístico-cultural. Este processo "é protagonizado por mediadores culturais que contribuem para a criação de narrativas temáticas patrimoniais como as rotas do contrabando, os museus do contrabando e da fronteira, as rotas de turismo cultural, etc.". Este turismo associado aos processos de patrimonialização parece alargar e esticar a fronteira "até levar o turista mais além da própria fronteira político-administrativa. As experiências turísticas recriam também novos limites sociais, mentais e simbólicos, que os humanos constroem nas relações com os outros. De facto, constata-se que, apesar da "queda da fronteira administrativa, a fronteira, no seu sentido de limite social, simbólico e mental redefinese através da experiência turística da relação com o outro".

Martín (2013) considera que a cultura é importante para abolir as fronteiras e exemplifica com o projeto ibérico conjunto Foz Côa - Siega Verde (Castilla y León). Os dois países colaboram intensamente com vista à conservação, proteção e valorização do território cultural, sendo que o expoente máximo foi a declaração da UNESCO de 2010 da afirmação de Siega Verde como uma ampliação de Foz Côa, classificado como Património Cultural de toda a Humanidade. De facto trata-se de um património num lugar comum de enorme potencial para o desenvolvi- 
mento atual e futuro destes territórios, por ser o único Sítio Cultural transnacional declarado Património Mundial. O objetivo principal é promover o desenvolvimento sustentável do território e das suas populações, pelo que esta perspetiva se enquadra na oportunidade de promover as aldeias e a sua articulação com vista à sua viabilização socioeconómica e melhorar a atratividade turística. Outro exemplo análogo é o Museu Arqueológico do Fundão, que conquistou por mérito próprio um lugar nas rotas de turismo da raia luso-espanhola (Rosa e Bizarro, 2013). Um dos seus projetos foi iniciado em 2010, designado de Scientia Ludica, que pretendeu através do intercâmbio cultural do Museu com outras entidades proporcionar a troca de experiências e conhecimentos dentro da máxima "aprender brincando e brincar aprendendo".

Na perspetiva de Salgado (2010), os produtos turísticos são bastante diversificados em Portugal e, em resultado da riqueza de recursos turísticos, tornam-se potenciadores de estratégias de desenvolvimento sustentável, quer a nível local, regional e mesmo nacional. Neste âmbito, revela-se importante implementar uma inventariação rigorosa dos recursos endógenos com vista ao seu conhecimento e à estruturação da oferta turística, com o intuito de promover produtos de qualidade e mesmo com uma projeção internacional. No seguimento desse estudo é necessário definir os recursos turísticos que determinam a vocação e a imagem turística desta região-destino fronteiriça alargada e, assim, promover o desenvolvimento de novos produtos turísticos de excelência (ex. rural, enogastronómico, ativo, entre muitos outros) classificados, em regra, como produtos de nicho (cf. Simões e Ferreira, 2009), funcionando como verdadeiros dinamizadores das políticas e das estratégias sectoriais do turismo, sobretudo projetando essa dinâmica a nível regional e transfronteiriço.

No seguimento desta reflexão, sobre os principais conceitos inerentes ao modelo de turismo de aldeia e às questões transfronteiriças mais relevantes, procede-se a uma breve caraterização geográfica das duas regiões, de modo a compreender melhor as relações existentes para estimular melhores estratégias de atuação conjunta.

\section{CARACTERIZAÇÃO GEOGRÁFICA}

A região Centro é uma das maiores regiões de Portugal, na qual se 
insere a Serra da Estrela (1993 metros de altitude no Planalto Central), sub-região de incidência do estudo. Possui um enorme potencial para se transformar num destino turístico relevante a nível ibérico, promovida por uma Entidade Regional única, responsável por integrar as políticas a nível turístico da região Centro. Os seus fatores de atração são caraterizados pela diversidade e riqueza inerente aos recursos turísticos existentes, bem como a localização geográfica, pela centralidade, e as boas acessibilidades, a hospitalidade dos residentes, os preços competitivos e o clima de segurança. Estas são apenas algumas das principais razões que se apontam para evidenciar o elevado potencial desta região, sobretudo para a atração de fluxos do mercado espanhol. No âmbito das áreas protegidas portuguesas, o Parque Natural da Serra da Estrela (PNSE) foi criado através do Decreto-Lei n. ${ }^{\circ}$ 55/76 de 16 de Julho, referindo tratar-se de "uma região de característica económica de montanha" onde subsistem "refúgios de vida selvagem e formações vegetais endémicas de importância nacional". A sua criação decorre da política levada a cabo no país com o objetivo de preservar e conservar o património natural de maior importância. Tem uma extensão aproximada de cem mil hectares, o mais extenso parque natural do país, que corresponde às áreas territoriais dos Concelhos de Celorico da Beira, Covilhã, Gouveia, Seia, Manteigas e Guarda. A delimitação deste Parque é feita em função de critérios de natureza física e dos recursos naturais, pelo que o limite dos concelhos que o integram não é coincidente com os limites do Parque.

Castela e Leão é uma comunidade autónoma da Espanha, que foi criada em 1983, conforme o seu estatuto de autonomia regional. Interessa caracterizar esta região pela extensa área de fronteira com a região Centro, bem como nela situar a Sierra de Francia (1723 metros de altitude no Pico Hastiala), na região sudoeste de Salamanca, e analisar o seu potencial turístico. A Sierra de Francia foi declarada Reserva da Biosfera pela UNESCO em 2006, sobretudo pelo seu valor natural, sendo uma região montanhosa com numerosos bosques e vales por onde fluem inúmeros rios. Está localizada a sul da província de Salamanca e possui uma extensão de 30 mil hectares em 14 municípios, fazendo parte do sopé ocidental da Cordilheira Central.

Estas duas regiões têm em comum serem integrantes do Sistema Central, que é uma cordilheira situada no centro da Península Ibérica, 
com uma orientação oeste-leste na sua metade oeste e orientação sudoeste-nordeste na sua metade leste. Tem uma longitude aproximada de 700 km e vai desde Portugal ao Sistema Ibérico. Constitui a separação natural entre a Beira Alta e Castela e Leão, ao norte, e Castela-La Mancha, Comunidade de Madrid, Estremadura e Beira Baixa, ao sul. Também representa a divisão da Meseta Central entre a submeseta norte e a submeseta sul.

Pode considerar-se que a paisagem é a melhor matéria-prima de que uma região dispõe, pois espelha e molda a cultura de um povo. É também um valor económico, um valor turístico e poderá ajudar a construir a imagem de um destino, a nível regional. A paisagem constitui, ainda, uma referência essencial da identidade das comunidades rurais e o enquadramento de espaços e atividades é cada vez mais valorizado pelas populações urbanas. A contemplação de uma paisagem pode ser a maior atracão de um lugar. Por tudo isto, o conceito de paisagem, seja natural ou humana, insere-se na definição de património turístico, podendo representar um poderoso potencial de atratividade para o destino. O turismo pode converter-se num meio de revalorização de paisagens que entraram em crise ou perdido funções tradicionais. Cabem, neste sentido, as iniciativas de turismo rural, que incluem a utilização de antigas casas rurais pelo turista, devidamente transformadas em pequenos estabelecimentos de alojamento, sobre os quais nos interessa conhecer a experiência dos hóspedes.

\section{METODOLOGIA}

Sabe-se que as opiniões dos turistas podem influenciar a imagem de um destino turístico, sobretudo tendo em conta os atributos mais valorizados no alojamento em meio rural. Os resultados ajudam académicos e profissionais a compreender as motivações e as necessidades dos hóspedes. Assim, a indústria do turismo pode projetar produtos e serviços mais personalizados para a satisfação do cliente. Devido à crescente atenção dada ao Facebook como ferramenta útil para fins relacionados com viagens, o estudo analisa o significado dos comentários, do ponto de vista do turista. Assim, a presente pesquisa visa fornecer informações sobre as seguintes questões:

Q1: Qual é a viabilidade de um destino turístico transfronteiriço entre as 
regiões Centro e de Castela e Leão com base no turismo rural?

Q2: Em que medida os atributos dos alojamentos em espaço rural são comentados no Facebook pelos hóspedes?

A fim de responder a estas questões de investigação, escolheu-se uma amostra o mais homogénea possível para melhor testar diferenças comportamentais decorrentes da leitura dos comentários dos hóspedes, que refletem as suas experiências nestas sub-regiões. Ambas as áreas possuem espaços naturais onde os visitantes podem fazer diversos tipos de atividades, como caminhadas, atividades em rio ou visitar as aldeias mais típicas e seus monumentos. Também têm um grande número de opções de alojamento para todos os tipos de visitantes (familias, jovens casais, grupos de pessoas, viajantes individuais ...).

Encontraram-se, assim, 72 opções de alojamento na Sierra de Francia e 334 na Serra da Estrela em Booking.com, que constitui uma opção intencional pelo maior universo de alojamentos disponíveis nesta plataforma. Escolheram-se os estabelecimentos com pontuação global superior a nove (pertencente à categoria excelente, de acordo com este portal online) para todos os comentadores. Em seguida, filtraramse os alojamentos para selecionar as opções com uma página ativa do Facebook. A partir desses alojamentos, selecionam-se os que apresentam mais comentários no Facebook, já que o objetivo é analisar dados provenientes das experiências fornecidas pelos visitantes. Uma vez que a amostra espanhola era menor, selecionaram-se menos alojamentos em Portugal para equilibrar os dados.

Usou-se a aplicação $\mathrm{N}$-capture para recuperar todas as mensagens e comentários do Facebook dos alojamentos selecionados em Espanha e Portugal. De seguida usou-se o software Nvivo10 para realizar a análise de conteúdo. Na primeira etapa da análise, identificou-se um conjunto de categorias relevantes para a análise. Utilizou-se uma versão adaptada de um dicionário de termos, que já foi utilizado na literatura (Nieto-García, Lahuerta-Otero e Muñoz Gallego, 2015, Encinas, 2015). De acordo com o dicionário, selecionaram-se 22 categorias relevantes. O próximo passo consistiu em examinar todas as opiniões dos diferentes usuários do Facebook para testar se havia diferenças significativas nas categorias analisadas. Também se realizou uma análise de crosscountry para verificar as diferenças nas opiniões dos usuários de redes sociais, dependendo do país. A amostra final foi constituída por 7 esta- 
belecimentos de Espanha e 10 de Portugal, com 105.811 referências com palavras pertencentes às 22 categorias do dicionário.

\section{ANÁLISE E DISCUSSÃO DOS DADOS}

Os resultados obtidos incluem o conjunto das unidades de alojamento em estudo (cf. figura 1). Porém, de seguida divide-se a amostra de acordo com o tipo de alojamento como aparece na plataforma Booking. com. Tem-se 4 opções diferentes, sendo a maioria casas de campo (11 de 17). O uso dessa variável, tipo de alojamento, ajuda a entender o panorama luso-espanhol nas redes sociais por tipologia. Da análise destaca-se que as páginas de fãs do Facebook, em média, são 4 vezes maiores em Portugal, o que pode ter impacto no número de comentários gerados, dado que o seu alcance é maior devido ao número de seguidores. Um resumo dos dados é apresentado na tabela 1, na qual se contata que os alojamentos portugueses têm mais fãs no Facebook (67\%) e os estabelecimentos com a categoria de casa de campo geram mais comentários (79\%). Também se destaca que o estabelecimento com a categoria de turismo rural gera 18\% do total de comentários da amostra.

\begin{tabular}{|c|c|c|c|c|c|c|c|c|}
\hline & \multicolumn{2}{|c|}{ País } & \multicolumn{2}{c|}{ Fãs no Facebook } & \multicolumn{4}{c|}{ Tipo de alojamento } \\
\hline & Espanha & Portugal & $\begin{array}{c}\text { Abaixo da } \\
\text { mediana }\end{array}$ & $\begin{array}{c}\text { Acima da } \\
\text { mediana }\end{array}$ & $\begin{array}{c}\text { Casa de } \\
\text { Campo }\end{array}$ & $\begin{array}{c}\text { Turismo } \\
\text { rural }\end{array}$ & Apartamento & $\begin{array}{c}\text { Casa de } \\
\text { Férias }\end{array}$ \\
\hline N.o de alojamentos & 7 & 10 & 9 & 8 & 11 & 1 & 2 & 3 \\
\hline$\%$ de alojamento & $41,18 \%$ & $58,82 \%$ & $52,94 \%$ & $47,06 \%$ & $64,71 \%$ & $5,88 \%$ & $11,76 \%$ & $17,65 \%$ \\
\hline N. o de referências & 34655 & 71156 & 20218 & 85593 & 83971 & 19294 & 1420 & 1126 \\
\hline$\%$ de referências & $32,75 \%$ & $67,25 \%$ & $19,11 \%$ & $80,89 \%$ & $79,36 \%$ & $18,23 \%$ & $1,34 \%$ & $1,06 \%$ \\
\hline
\end{tabular}

Tabela 1: Distribuição de comentários do Facebook por tipo de alojamento

No seguimento da análise da distribuição de comentários do Facebook, por tipo de alojamento, apresenta-se a tabela 2, que inclui o número de referências associadas a cada uma das categorias do dicionário, resultante dos comentários dos visitantes nas páginas de fãs do Facebook nos alojamentos selecionados, em Espanha e em Portugal. Constatase que apenas 8 das 22 categorias são mencionadas em todos os 17 alojamentos da amostra e, em geral, de modo significativo, exceto o quarto e a época. $\bigcirc$ conjunto das categorias representa os atributos dos alojamentos, sendo que a categoria de serviços adicionais inclui 
outro atributo que não estava referido na listagem.

\begin{tabular}{|l|c|c|c|}
\hline \multicolumn{1}{|c|}{ Categorias } & Referências & Alojamentos & Percentagem de referências \\
\hline Acesso & 327 & 11 & $0,31 \%$ \\
\hline Acomodação & 13718 & 17 & $12,96 \%$ \\
\hline Serviços Adicionais & 734 & 13 & $0,69 \%$ \\
\hline Limpeza & 550 & 14 & $0,52 \%$ \\
\hline Conforto & 147 & 10 & $0,14 \%$ \\
\hline Decoração & 110 & 7 & $0,10 \%$ \\
\hline Distância & 13419 & 17 & $12,68 \%$ \\
\hline Equipamentos & 13035 & 17 & $12,32 \%$ \\
\hline Alimentação & 3993 & 16 & $3,77 \%$ \\
\hline Hospitalidade & 1650 & 16 & $1,56 \%$ \\
\hline Informação & 80 & 10 & $0,08 \%$ \\
\hline Manutenção & 7 & 4 & $0,01 \%$ \\
\hline Multimédia & 2006 & 15 & $1,90 \%$ \\
\hline Parque & 12894 & 17 & $12,19 \%$ \\
\hline Preço & 520 & 12 & $0,49 \%$ \\
\hline Restaurante & 500 & 12 & $0,47 \%$ \\
\hline Quarto & 2255 & 17 & $2,13 \%$ \\
\hline Época & 2070 & 17 & $1,96 \%$ \\
\hline Espaço & 354 & 10 & $0,33 \%$ \\
\hline Clientes Especiais & 13142 & 17 & $12,42 \%$ \\
\hline Temperatura & 261 & 13 & $0,25 \%$ \\
\hline Atraçães Turísticas & 105811 & & $22,72 \%$ \\
\hline TOTAL & & 17 & \\
\hline
\end{tabular}

Tabela 2 - Distribuição dos comentários de acordo com as categorias

Nesta tabela pode-se observar que atrações turísticas é a categoria mais mencionada no Facebook pelos visitantes, por gerar 22,72\% do total de referências. Outras categorias como acomodação, distância, equipamentos, estacionamento e clientes especiais (familias, crianças, animais de estimação...), também possuem elevada percentagem de referências neste estudo. Pelo contrário, a manutenção tem um número muito limitado de referências, estando presente apenas em 4 dos 17 estabelecimentos analisados. Nos comentários associados às categorias do estudo, nas duas sub-regiões em apreço, constata-se um comportamento análogo nas categorias mais comentadas nos dois países, pelo que os resultados gerais da tabela 2 são, em regra, proporcionalmente distribuídos pelas duas partes da amostra. Os resultados também mostram que os estabelecimentos portugueses obtêm substancialmente mais comentários do que os espanhóis (71156 versus 
34655) sobre o total das categorias deste estudo.

\section{CONCLUSÃO}

A procura turística exige, cada vez mais, novos produtos em destinos que possuam um modelo de turismo sustentável, que também depende das características e da qualidade dos alojamentos e seus serviços. Esta realidade reflete as preocupações crescentes com a conservação dos recursos de suporte das atividades turísticas. A reflexão sobre a sustentabilidade no turismo permite evidenciar a necessidade de integração dos interesses da população local, dos turistas e da própria indústria turística, bem como a necessidade de conservação do património natural e cultural no desenvolvimento de uma área-destino. Quando se trata de áreas rurais e protegidas, o turismo deve ser planeado numa perspetiva de desenvolvimento integrado, promovendo a articulação com outras atividades económicas e regiões, com o intuito de melhor corresponder às expetativas do mercado turístico. A procura deste mercado é cada vez maior e mais exigente, procurando novos produtos e novos destinos, designadamente internacionais.

Deste artigo pode concluir-se sobre a importância crescente que o turismo pode assumir nestas regiões de fronteira. As relações estabelecidas pelo turismo com o espaço são cada vez mais fortes, daí ser considerado um fenómeno estruturante de base territorial, suportado nos recursos naturais, culturais e humanos. Os produtos turísticos âncora podem ser, assim, uma alavanca das politicas e das estratégias sectoriais, sobretudo projetando essa dinâmica ao nível transfronteiriço no contexto do turismo de aldeia em regiões de interior da região Centro e da de Castela e Leão. É possível afirmar o interesse manifestado pelos vários autores referidos na secção 1.2 sobre este destino turístico transfronteiriço, mas também é uma realidade oportuna noutras regiões da fronteira portuguesa e espanhola, pelo que consideramos aceitar a viabilidade de uma gestão integrada a nível turístico entre estas duas regiões semelhantes, particularmente suportada nas características das sub-regiões da Serra da Estrela e da Serra de Francia. Por outro lado, os argumentos do trabalho integrado apoiam-se nas semelhanças das perspetivas da procura turística estudada, com base nas semelhanças 
dos atributos valorizados analogamente nos comentários dos hóspedes, bem como nas semelhanças em termos das características das ofertas turísticas destas duas regiões de destino transfronteiriço.

Na discussão dos dados recolhidos reconhece-se que o E-turismo e F-turismo são uma tendência recente entre académicos e profissionais, desde que os usuários da Internet mudaram a forma como compartiIham conteúdos relacionados às viagens. A indústria do turismo supõe conhecimento intensivo e beneficia das tecnologias, de várias maneiras. O F-turismo fornece um novo, rápido, detalhado e atraente espaço virtual onde os visitantes podem compartilhar as suas experiências. As empresas precisam de estar cientes da necessidade de criar, manter e aprimorar os seus perfis sociais, como um meio de se envolverem com o seu global e heterogéneo público. Hoje, reconhece-se o poder de revisões dos comentários, que informam e convencem futuros clientes sobre um determinado destino turístico. Dado que os visitantes têm uma imagem preliminar limitada do destino turístico, contam com as opiniões de outros clientes para reduzir o risco associado a cada escolha.

As redes sociais contribuem para criar um círculo virtuoso, pois uma experiência positiva no estabelecimento de alojamento transforma-se, em regra, num cliente satisfeito. Então, os clientes satisfeitos estão dispostos a compartilhar as suas experiências positivas com outros visitantes através de redes sociais. Os estabelecimentos que se envolvem com os seus clientes no Facebook obtém mais fãs e mais opiniões dos clientes, aumentando o alcance da página. Portanto, as análises de redes sociais ajudam os clientes futuros a reduzir o risco de compra associado ao escolher um destino turístico. Como as páginas de fãs do Facebook alavancam as oportunidades de comunicação (Salgado, Martins \& Godinho, 2013), se as empresas promovem, incentivam e cuidam dos fãs nas suas redes sociais também podem descobrir mais sobre as suas experiências de viagem. Eles também podem observar as características do alojamento que os clientes mais gostam e quais as necessidades de melhoria. Estas contribuições valiosas são fornecidas gratuitamente, de modo que os estabelecimentos só precisam de estar cientes das opiniões dos clientes. Os turistas precisam de mais do que um simples lugar para dormir, pelo que estas regiões, com património natural, cultural e histórico, constituem um ambiente oportuno para construir um destino interessante, pois a Serra da Francia e a Serra 
da Estrela oferecem inúmeras atividades de lazer. Os hóspedes das diferentes acomodações rurais usam o Facebook para recolher mais informações, obter recomendações e fazer planos de viagem. Esta será a razão pela qual a categoria atrações turísticas é o atributo mais comentado em todos os tipos de alojamentos, tanto em Espanha como Portugal.

Conforme analisado no enquadramento geográfico, as duas áreas são semelhantes e compartilham normas, tradições e valores culturais do meio rural. Portanto, pode-se esperar que os clientes comentem sobre esses mesmos atributos. No entanto, os diferentes atributos do alojamento em Espanha e Portugal podem verificar-se pelas páginas do Facebook para fazer benchmarking e, assim, melhorar os seus próprios serviços. A informação sobre concorrentes está igualmente disponível para a indústria turística, de modo a que as organizações e empresas públicas também podem usar esses dados para criar, promover ou desenvolver novos serviços para melhorar a imagem do destino turístico e aumentar a estada média dos clientes.

$\mathrm{Na}$ tabela 2 observa-se que atrações turísticas é a categoria mais mencionada no Facebook pelos visitantes (22,72\%). Outras categorias como acomodação, distância, equipamentos, estacionamento e clientes especiais (familias, crianças, animais de estimação...), também se revelam importantes atributos pelas referências feitas pelos hóspedes. Assim, consideram-se oportunas as análises efetuadas, sobretudo para legitimar a ideia de que os turistas de uma região usam bastante o Facebook para partilhar as suas experiências de viagem em alojamentos em espaços rurais. A pesquisa também permitiu compreender e aceitar alguns atributos mais relevantes que são reconhecidos e valorizados pelos hóspedes nos alojamentos em espaço rural.

Deve-se mencionar algumas limitações deste estudo, pois este estudo é essencialmente qualitativo e exploratório, pelo que precisa de ser melhor aprofundado no estudo empírico, designadamente na dimensão da amostra, de modo a suportar melhor o modelo de desenvolvimento turístico transfronteiriço em apreço. Os resultados pertencem a uma fonte, pois o presente estudo apenas analisa o texto dos comentários em páginas do Facebook e não tem em conta imagens, links ou emoções. As futuras linhas de pesquisa podem também concentrar-se no impacto da eWOM na experiência de serviço, ampliando a análise 
dos atributos. Pode-se expandir a pesquisa analisando os comentários dos visitantes sobre outras redes sociais ou blogs, bem como aumentar o número de países para testar as diferenças entre culturas.

\section{BIBLIOGRAFIA}

Aguado, A. D. G. (2013), La Planificación Turística en Castilla y Leon: del Plan de Territorio al Plan de Producto, Arcos, F. J. M. (ed.), Turismos de Interior: Planificación, Comercialización y Experiencias, Ediciones Pirámide, Madrid, pp. 127 137.

Arcos, F. J. M. (2013), Turismos de Interior: Planificación, Comercialización y Experiencias, Ediciones Pirámide, Madrid.

Augusto, D. D., Pinho, J. C., Rodrigues, C. J. (2010), Análise integrada multissectorial e pluridimensional no território, Revista Turismo e Desenvolvimento, 13/14 (2), 499-511.

Buhalis, D. (2000), Marketing the competitive destination of the future; Tourism Management, pp. 97-116.

Capela, C., Figueiredo. E. (2014), 'Mergulhar num mundo mágico': A promoção do rural em três redes de aldeias em Portugal, Revista Turismo e Desenvolvimento, 13/1 4 (2), 377-389.

Cunha, L., Abrantes, A. (2013), Introdução ao Turismo; $5^{a}$ Edição, Lidel, Lisboa. Dias, D. M. (2013), Ateliers design thinking and doing. Uma abordagem concetual como contributo para o desenvolvimento sustentado do território das aldeias históricas de Portugal, Frías, M. S. (ed), Interpretar la Frontera: Jornadas de Património, Turismo y Desarrollo Local, Ediciones de la Deputación de Salamanca, Salamanca.

Encinas, L. G. (2015). Análisis sociológico del consumo turístico en España. Cambios en el sector de viajes y representaciones colectivas sobre vacaciones, Doctoral dissertation, Universidad Nacional de Educación a Distancia.

Kastenholz, E. Eusébio, C. Figueiredo, E. Carneiro, M. \& Lima, J. (2014), Reinventar o turismo rural em Portugal - cocriação de experiências turísticas sustentáveis, UA Editora, Aveiro.

Kotler, P., Bowen, J.T., \& Makens, J.C. (2010), Marketing for Hospitality and Tourism. International $5^{\circ}$ Edition: Pearson.

López, D. S. (2013), Caracterización Territorial de la Raya lbérica. El Ámbito de la Frontera entre Portugal Y España. Castilla y Leon, Fernández, A. J. C. (ed.), Turismo de Frontera (I), Ediciones RIET, Vigo, pp. 37-50.

López-Guzmán, T., Orgaz-Agüera, F., Ribeiro, M. A. (2015), Contributos da gastronomia em destinos turísticos fronteiriços em desenvolvimento: Um estudo de 


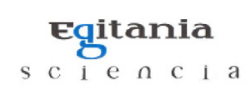

caso, Revista Turismo e Desenvolvimento, 24, 9-20.

Martín, E. S. (2013), Cultura para abolir las fronteras: Foz Côa - Siega Verde, Frías, M. S. (ed), Interpretar la Frontera: Jornadas de Património, Turismo y Desarrollo Local, Ediciones de la Deputación de Salamanca, Salamanca.

Mateus, A., Simões, A., Alvarez, C., Macias, J. I. S. Rodrigues, G. C. H., Kastenholz, E., Sunyer, C. (2009), Road-book do Projeto MIT - Mobilidade, Inovação e Território, CCDRC, Coimbra.

Moreno, F. J. J. (2013), El Turismo en Regiones de Frontera. Castilla y Leon, Fernández, A. J. C. (ed.), Turismo de Frontera (I), Ediciones RIET, Vigo, pp. 69-78. Nieto-García, M., Lahuerta-Otero, E. \& Muñoz-Gallego P.A. (2015) La experiencia de los turistas en alojamientos de turismo rural de la provincia de Ávila a través de sus mensajes en Internet. En Centro de Análisis e Innovación turística de la provincia de Ávila. Boletín Turístico, 2-2015, pp. 27-44.

Pereira, V. C., Pereira, X. (2014), Turismo transfronteiriço na Euro-região Galiza-Norte de Portugal, Revista Turismo e Desenvolvimento, 21 /22 (2), 285-294. Rodrigues, A. \& Rodrigues, A. (2009). Turismo e Inovação em Espaços Rurais: estudo de caso da rede europeia de turismo de aldeia. Revista Turismo em Análise, 20, n. 1 .

Rosa, J. M., Bizarro, J. (2013), O passado como elemento de formação cívica e incremento turístico. O caso do Museu Arqueológico do Fundão, Frías, M. S. (ed), Interpretar la Frontera: Jornadas de Património, Turismo y Desarrollo Local, Ediciones de la Deputación de Salamanca, Salamanca.

Salgado, M. A. B. (2010), Perspetivas do turismo rural em Portugal, Moreno, F. J. J., Arcos, F. J., M. (eds.), Estudios de Turismo Rural y Cooperación entre Castilla y León y Portugal, Ediciones Universidad, Salamanca, pp. 49-63.

Salgado, M. A. B., Martins, J. A. S. V., Godinho, A. N. (2013), Redes sociais como veículo de informação turística de destinos a nível regional, Innovation and Technology in Tourism and Hospitality, Coleção Politécnico da Guarda, 9, 47-61. Simões, J. M., Ferreira, C. C. (2009), Turismos de Nicho, Motivações, Produtos, Territórios, Universidade de Lisboa, Centro de Estudos Geográficos, Lisboa. 